\title{
PSYCHOLOGICAL ASPECTS AND PSYCHOTHERAPY OF INFLAMMATORY BOWEL DISEASES AND IRRITABLE BOWEL SYNDROME IN CHILDREN
}

\author{
Jan Prasko ${ }^{\mathrm{a}}$, Daniela Jelenova ${ }^{\mathrm{a} *}$, Vladimir Mihal ${ }^{\mathrm{b}}$ \\ ${ }^{a}$ Department of Psychiatry, Faculty of Medicine and Dentistry, Palacky University and University Hospital Olomouc, Czech \\ Republic \\ ${ }^{b}$ Department of Paediatrics, Faculty Medicine and Dentistry, Palacky University and University Hospital Olomouc \\ E-mail: daniela.jelenova@fnol.cz
}

Received: April 29, 2010; Accepted: July 21, 2010

Key words: Inflammatory bowel disease/Crohn's disease/Ulcerative colitis/Irritable bowel syndrome/Quality of life/ Psychological problems/Cognitive behavioral therapy

Backround. Despite holistic approach to psychosomatic medicine, gastroenterological disorders (GI) tend to be categorized broadly into "functional" and "organic". Major GI illnesses are Inflammatory bowel diseases (IBD) include ulcerative colitis and Crohn's disease. Both are chronic, with remissions and relapses over the years while irritable bowel syndrome (IBS) is a common, often disabling functional gastrointestinal disorder.

Methods. A literature review was performed using the National Library of Medicine PubMed database, including all resources within the period 1991-2008, additional references were found through bibliography reviews of relevant articles.

Results. Psychological problems: Higher scores of neuroticism, depression, inhibition, and emotional instability, are typical for many patients with chronic diseases and nonspecific for chronic gastroenterological disorders. Patients with chronic gastrointestinal disorders have impaired health-related quality. Psychological treatments: There have been few adequate psychological treatment trials in IBD. These achieved lower demands for health care rather than a reduction of anxiety or depression. Psychotherapy with chronic gastrointestinal disorders could lead to improve the course of the disease, changing psychological factors such as depression and dysfunctional coping and improving the patient's quality of life.

Conclusions. There seem to be "risk patients" in whom psychosocial components have a bigger influence on the course of disease than in other patients; and those would probably benefit from psychotherapeutic treatment. Psychological treatments help patients manage the psychological distress which worsens bowel symptoms and quality of life.

\section{INTRODUCTION}

In the $21^{\text {st }}$ century a bio-psycho-social model of disease is being appraised. This implies an appreciation that genetic and early environmental factors may shape an individual's predisposition to disease, on which biological, psychological, and social variables may determine the onset and subsequent course of a clinical disorder ${ }^{1}$. Despite the holistic approach to psychosomatic medicine, gastroenterological disorders tend to be categorized broadly into "functional" and "organic". This has some advantages and many disadvantages. The distinction helps facilitate research into the psychological factors that are important in the etiology, presentation, and outcome of the "functional" disorders. The research has been multidisciplinary and has led to a clear conceptualization of the biopsychosocial model in gastroenterology ${ }^{2}$. This is important because such disorders comprise approximately half of all new patients seen by gastroenterologists. The most prominent disadvantage of the functional and organic division is the apparent reinforcement of dualistic thinking; for example peptic ulcer, previously regarded as a psychosomatic condition, is now regarded as a purely biological one, and psychosomatic aspects tend to be ignored ${ }^{3}$. Another problem is some gastroenterologists falsely equate functional with psychiatric, and may give the impression complaints based on a demonstrable abnormality (e.g. by gastroscope visualization) are "real," whereas other complaints may be dismissed as they turn out to be only functional and are the responsibility of a psychiatrist or of the patients themselves. Since the mid1990s, a symptom-based classification of the functional gastrointestinal disorders, the "Rome" criteria, has been developed ${ }^{4}$. This is similar in concept to the $\mathrm{DSM}^{5}$, and the use of these two schemas has greatly aided research into the psychological aspects of functional gastrointestinal disorders 6 . Such a classification has caused much discussion among gastroenterologists who are accustomed to making diagnoses on the basis of observable pathological abnormalities.

IBD include ulcerative colitis and Crohn's disease. Both diseases are chronic, with remissions and relapses over the years. Symptoms include diarrhea, abdominal cramps, pain, weight loss, and bleeding from intestines. Both biological and psychological factors are independent determinants of impairment in patients IBD. IBS is a 
common, frequently disabling functional gastrointestinal disorder whose full range of symptoms (abdominal pain/ discomfort with altered bowel habits such as diarrhea and/or constipation) is generally unresponsive to conventional therapy. The few effective medications developed specifically for IBS have either been withdrawn or severely restricted in response to concerns about safety, creating an urgent need to develop behavioral self management treatments that could train patients to adopt effective strategies for relieving symptoms unresponsive to available dietary or pharmacological agents.

A few years after Crohn's disease was firstly describ$\mathrm{ed}^{7}$, speculations about psychosomatic etiology/influences arose and these were discussed in the same way as ulcerative colitis ${ }^{8}$. As a result, researchers tried to identify typical personality traits, specific conflict constellations and/or psychiatric abnormalities in the case of IBDs but these failed in consistency and specificity.

\section{STRESS AND INFLAMMATORY BOWEL DISEASES}

Psychosomatic research hypothesized some psychosocial factors could help trigger relapses. An increased stress appears to facilitate disease reactivation. IBDs can be affected by stress ${ }^{9,10}$. Stress modulates colonic motility ${ }^{11}$ and it influences the endocrine and immune system which are mediators of the inflammatory process. The disease activity in IBDs might be affected by stress-related factors (vasoactive intestinal protein, tumor necrosis factor $\alpha)^{12}$. Elevated stress levels or life events increased the relapse risk in patients with ulcerative colitis ${ }^{13}$. IBS and IBDs have significantly greater stress burdens than controls ${ }^{10}$ and higher levels of psychiatric distress, alexithymia and somatosensory amplification ${ }^{14}$. Unlike short-term stress, the perception of chronic stress appears to increase the risk of exacerbation of ulcerative colitis ${ }^{13}$.

Active IBD is significantly related to impaired psychological functioning across a range of domains, whereas inactive disease is not ${ }^{15}$. IBDs in remission had similar psychological well-being to the non-inflammatory bowel disease community sample. In Crohn's disease patients, well-being was comparable regardless of whether remission was surgically or medically induced ${ }^{16}$.

In the Canadian Community Health Survey (sample size of 132,947 Canadians) the IBDs (4,441 participants) were more likely to experience fair or poor general health ${ }^{17}$. IBS patients reported higher levels of stress and poorer mental health than IBDs. When IBS or IBD coexisted with another chronic condition, active participation at home and at work was significantly more likely to be impaired.

IBS is also associated with several other conditions, notably other bowel disorders, chronic fatigue syndrome, and fibromyalgia ${ }^{18,19}$. The presence of untreated psychiatric disorder predicts a poor outcome ${ }^{20}$.

\section{INFLAMMATORY BOWEL DISEASES AND QUALITY OF LIFE}

Physical complaints as well as mental problems can adversely affect a patient's quality of life (QOL), as proved in studies of patients with ulcerative colitis and Crohn's disease $^{21,22}$. The number of patients with chronic functional gastrointestinal disorders is increasing and consequently the prevalence of psychiatric disorders. It is widely recognized that people with IBD have impaired health-related QOL ${ }^{20,23}$, but recent studies emphasized concurrent anxiety and depressive and panic disorders as major causes of this impairment ${ }^{24,25}$. In dyspepsia, psychological distress is a better predictor of health-related QOL than the severity of the dyspepsia ${ }^{26}$. In IBS factors predicting health-related QOL are a combination of psychiatric disorders (depressive, panic, or neurasthenia) or symptoms (easily fatigued and low in energy) and severe bowel symptoms, notably pain ${ }^{24}$.

Health-related QOL is impaired in IBS and dyspepsia sufferers compared with healthy controls ${ }^{25,27}$. A recent thorough study found how the degree of somatization mediates the negative effect of anxiety and depression on the physical component score of the Medical Outcomes Scale SF-36 (limitations on daily life imposed by the illness, associated bodily pain, and impaired physical functioning $)^{25}$. The relation between impaired health-related QOL and subjects with IBS and dyspepsia can be explained by psychological factors. The depression reduction in the patients undergoing psychological treatments was associated with improved health related $\mathrm{QOL}^{24}$.

In clinic studies, especially at tertiary care centers, there has been found an association between sexual and physical abuse and functional gastrointestinal disorders, but findings are not consistent ${ }^{28,29}$. A high rate of reported childhood abuse is not unique to patients with functional gastrointestinal disorders because similar high rates are also reported by patients with other chronic or recurrent painful functional conditions, such as pelvic pain, headaches, and fibromyalgia ${ }^{30,31}$. Since a history of abusive experiences is closely related to poor health outcomes (severe abdominal pain, marked impairment of functioning, and frequent visits to the doctor), there might be an association with concurrent psychiatric disorder rather than with history of abuse ${ }^{23}$.

\section{IBD RELATED PSYCHOLOGICAL AND PSYCHIATRIC PROBLEMS}

There are high levels of psychiatric disorders across diagnostic groups such as IBS, functional dyspepsia, functional abdominal pain, and noncardiac chest pain ${ }^{32,33}$. Anxiety is more prominent in first-time attenders with IBS, but depression seems to be more prominent in those with chronic symptoms and a long period without remission $^{34,35}$. The group of patients with gastrointestinal symptoms as a part of their panic disorder, may be an atypical group of functional gastrointestinal disorder 
patients $^{36}$. IBDs have a higher prevalence of anxiety and depressive disorders than the general population, but a lower prevalence of these disorders than patients with functional bowel disorder ${ }^{5}$. The rate $(21-35 \%)$ is similar to the one found in other patients with chronic physical illness ${ }^{37}$. Depressive disorder appears to be more common in older patients and in those with a previous history of psychiatric disorder ${ }^{38}$.

In a cross-sectional clinic-based study included patients with recent onset of both peptic ulcer and IBD ${ }^{39}$ only $16 \%$ had define psychiatric disorders but a further $32 \%$ had subthreshold psychiatric disorders. A recent onset of nonspecific symptoms of tension, worry, and irritability together with mild mood disorders was common in these patients with recent onset IBD or peptic ulcer.

Two prospective clinical studies of patients with IBD appear to produce conflicting results. During a 6-month follow-up period, one study found a strong association between change in disease activity and anxiety level and a weaker association with depressive symptoms ${ }^{40}$. Changes in disease activity seemed to lead to changes in anxiety and depression. Beck Depression Inventory scores at baseline predicted number and timing of relapses during an 18-month follow-up period ${ }^{41}$.

The presence of additional gastrointestinal symptoms (defecation, bloating, altered bowel habit) is associated with the greatest impairment of health-related QOL of all patients with $\mathrm{IBD}^{42}$. Thus, the relationship between psychiatric disorders and IBD is unclear. Some investigators suggested a possible vulnerability of certain patients with IBD to develop a psychiatric disorder due to experiences that are independent of the disease process (e.g., childhood victimization and abuse) (ref. ${ }^{43}$ ).

Many authors report psychiatric disorder only in close relationship with increased disease activity, suggesting that the former may be a consequence of disease activity ${ }^{44}$. A population-based linkage study identified contacts with psychiatric services for 5 years before and 5 years after the initial diagnosis of IBD in a total population of more than 2 million people during 36 year period ${ }^{45}$. Both depression and anxiety were more prevalent during the year before diagnosis of ulcerative colitis compared with the control population. There was no similar excess of anxiety or depression before the diagnosis of Crohn's disease. However, both anxiety and depression were much more common in the year immediately following diagnosis of Crohn's disease and ulcerative colitis. The excess of anxiety or depression during the year subsequent to the diagnosis of IBD might be due to a reaction to the diagnosis of IBD, it could also result from the use of medication (steroids). These are impressive results, especially because this study included psychiatric patients only; though many people with anxiety and depressive disorders would not go to see a psychiatrist.

Important personality factors in ulcerative colitis were neuroticism and locus of control, while in Crohn's disease there was social conformity/desirability together with neuroticism ${ }^{46}$. IBDs often have high level of dependence on others and low levels of hostility and aggression ${ }^{47}$. Unlike patients with a high level of dependence on others, people with internal locus of control are generally less distressed in stressful situations, which might be associated with better disease-specific QOL ${ }^{48}$. In contrast, hostility and other aggressive personality traits might have a negative impact on the QOL. In adolescents with IBD, hostility is related to higher level of subjective illness, and hostility is generally related to poor health habits and interpersonal conflicts $^{49}$.

\section{PSYCHOTHERAPEUTIC APPROACHES TO PEOPLE WITH IBD}

The suspected connection between psychological factors and relapses leads to the question whether psychotherapy would be beneficial to IBDs. There have been a few adequate psychological treatment trials in IBD. Of these, lower demands on health care were achieved rather than a reduction of anxiety or depression. Psychotherapy with IBDs could improve the course of the disease, reduce psychological factors such as depression and dysfunctional coping and better the quality of life. Ten studies were conducted on the effects of psychotherapeutic treatment of patients with $\mathrm{IBD}^{50}$. In all studies, patients received conservative therapy and, simultaneously, the psychotherapy was used as a supplementary treatment. The studies presented two main approaches of psychotherapy:

1. Psychodynamic therapy (including psychoanalysis and supportive-expressive therapy)

2. Behavioral therapy (predominantly stress management training). Psychodynamic therapy addresses more underlying problems and conflicts, and the behavioral therapy addresses more specific problematic cognitions and dysfunctional behavior.

\section{STUDIES INVOLVING PSYCHODYNAMIC PSYCHOTHERAPY}

The first study regarding the effectiveness of psychotherapy for ulcerative colitis was conducted 50 years ago $^{51}$, but unfortunately, it was methodologically poor-quality. The effects of supportive psychotherapy on the course of the disease and coping skills in patients with Crohn's disease were investigated in 1987 (ref. ${ }^{52}$ ). The scores for depression and anxiety decreased significantly during the 13 months while the study was being conducted. There were no differences in regard to most of the somatic data.

The effect of psychodynamic psychotherapy on patients with Crohn's disease was investigated in a randomized, multicenter study ${ }^{53}$. The psychotherapeutic intervention consisted of psychodynamic psychotherapy (26 sessions) and autogenic training (17 sessions). After 2 years, a relapse has not been experienced by $23 \%$ of the control group and 30\% of the therapy group. $29 \%$ of the control group and $17 \%$ of the therapy group had to undergo surgery. The therapy group had better somatic data than the control group but not significantly so. After 1 year, the scores for depression, anxiety, quality of life, and psychological symptoms did not differ significantly, 
but mostly were within the normal range. In another study, the scores for maladaptive coping decreased significantly over the course of treatment in patients with IBD who underwent 20 weekly sessions of supportiveexpressive group psychotherapy covered emotion-evoking issues and discussions about disease related topics (such as self-image, stigma, and conflict with health care professionals) (ref. $\left.{ }^{54}\right)$.

\section{COGNITIVE BEHAVIORAL THERAPY}

Cognitive behavioral therapy (CBT) is a time limited, structured, problem focused, and prescriptive therapy based on two central underlying assumptions:

1. Symptoms are acquired (learned) and reflect specific skills deficits in domains of cognitive and behavioral functioning.

2. Teaching and rehearsing skills for modifying maladaptive behaviors and thinking patterns can remediate these deficits which, in turn, relieve symptoms.

Specific technical components of CBT protocols typically include: (a) information on stress and its relationship to IBS; (b) self monitoring of antecedent and consequent events associated with IBS flare ups; (c) problem solving strategies around stressors that aggravate symptoms; (d) muscle relaxation exercises for cultivating lower physiological arousal and increased sense of mastery over symptoms; (e) cognitive restructuring for modifying faulty threat appraisals that underlie physiological and emotional reactivity.

An overarching goal of CTB is to teach skills for patients to take proactive role in controlling symptoms, cope with emotional unpleasantness, and improve quality of life. CBT has been found to be effective in hospital patients with IBS, however recent trials have reported equivocal results ${ }^{55,56}$. A number of clinical trials support the efficacy of CBT when administered over multiple (weekly) sessions by trained therapists in tertiary care settings ${ }^{57,58}$ - the outcomes include improvement in key gastrointestinal symptoms (pain, bowel dysfunction), quality of life ${ }^{59}$, and psychological distress ${ }^{60}$. CBT has practical limitations (high cost, shortage of adequately trained therapists, long waiting lists, time requirements) that hamper its clinical utility. As the "second generation" of IBS treatments under development, it is increasingly clear that efficacy demonstration is a necessary but not sufficient condition of treatment viability for IBS treatments.

Cognitive based models have been proposed in the etiology and maintenance of IBS: these patients are hypothesized to hold the faulty belief that they have an organic GI abnormality. Based on this schema, hyperalgesia would be a consequence of IBS ${ }^{61}$. Patients with IBS more selectively recall words describing GI sensations than neutral words compared to healthy controls ${ }^{62}$. A genetically predetermined visceral hypersensitivity can lead to symptoms of IBS. Patients become hypervigilant to GI sensations and develop cognitive distortions, interpreting the sensations as threatening. These threats increase anxiety, which in a vicious cycle directly affects the gut, causing further symptoms of IBS $^{63}$. Both of the above hypotheses support a cognitive behavioral theory of IBS. Psychotherapists attempt to break the feedback loop described above by addressing dysfunctional cognitions such as catastrophic thinking and by decreasing overall anxiety. Due to CTB treatment, less negative thoughts were associated with greater amelioration of symptoms ${ }^{64}$. Unfortunately, studies of psychological treatment trials in patients with IBS are of poor quality with small sample sizes, poor randomization or inadequate blinding ${ }^{19}$; or researchers use varying definitions of IBS ${ }^{56}$. Nonetheless, several controlled trials have reported $\mathrm{CBT}$, or CBT-like treatment, to be effective in patients with IBS.

No significant differences were found in a controlled comparison of individual versus group CBT for patients with IBS; at the end of treatment only $10 \%$ of the waiting list of control patients had improved bowel symptoms compared to $55 \%$ patients receiving individual treatment and $64 \%$ of patients receiving group treatment ${ }^{65}$.

\section{Individual CBT-like treatment}

Individual CBT-like treatment in IBS patients was found to be superior to a self-help support group or a wait list control; both individual gastrointestinal symptoms and a composite index of overall symptoms were reduced ${ }^{66}$.

The effectiveness of two stress management programs for patients with Crohn's disease was studied ${ }^{67}$. Fewer complaints with fatigue, constipation, abdominal pain and distension were expressed by patients from group " $\mathrm{A}$ " (received 6 individual sessions of manualized stress management) and group "B" (received a self-directed stress management program and relaxation training) over control group "C" (conventional medical treatment).

A special summer camp proved to be helpful for children with $\mathrm{IBD}^{68}$. The 9-16 year old children had no formal IBD educational classes but many informal conversations among the campers and between campers and counselors about their illness. The campers participated in leisure group activities such as swimming, basketball, arts. The total scores for health related QOL improved, and so did bowel symptoms scores, social functioning scores, and treatment interventions scores.

Patients after a 2 hour patient-orientated self management program had significantly fewer hospitalizations than control group during 1 year follow-up ${ }^{69}$. However, the scores for quality of life, anxiety, and depression were not significantly different.

Patients with ulcerative colitis in remission participated in 60 hour training program of "Mind-BodyTherapy" including stress management training, exercise, Mediterranean diet, behavioral techniques, and self-care strategies $^{70}$. Statistically significant changes were noted only regarding the mental health scale and QOL. In contrast there were no differences concerning somatic data such as disease activity, endocrine, and immune parameters.

Female patients with functional bowel disorders (including IBS, functional abdominal pain, painful con- 
stipation, and unspecified functional bowel disorders) showed statistically significant benefits when treated with CBT compared to patients treated with education only ${ }^{55}$. Patients with comorbid depression did not appear to benefit from CBT.

\section{Group CBT-like treatment}

Reduction of abdominal complaints was greater in patients with IBS who received group CBT than those in a waiting list ${ }^{71}$. Additionally, patients who received group therapy developed a greater number of useful coping strategies and less avoidant behavior. The results persisted at 2 years follow-up.

6 hours of stress management training focused on planning techniques (time management, problem solving), communication skills, and relaxation (autogenic training) improved the disease activity and stress index in $\mathrm{IBD}^{72}$.

12 sessions of group CBT consisted of psychoeducation about IBD, factors of stress creation, coping strategies for disease-related and routine stress, and progressive muscle relaxation training ${ }^{73}$. Even after 9 months of the therapy, patients with IBD had lower scores of depression and illness-related anxiety; in addition, female patients had better ability to cope.

A 12 hour educational program involved general information about anatomy, pathophysiology of IBD, therapy, and discussions ${ }^{74}$. Higher knowledge scores and patient satisfaction remained 8 weeks; no significant effect was found in QOL or medication adherence.

\section{Trials without psychotherapeutic effect}

In contrast with the above findings, several trials found no therapeutic effect of such interventions and in one study, all patients with IBS showed significant improvement in self-reported GI symptoms, regardless of treatment type (CBT or relaxation training, or care as usual) ${ }^{56}$.

Outpatient behavioral therapy with IBD had similar somatic symptoms and psychological variables to the waiting list control group ${ }^{75}$. Most patients in the 12 hour therapy group (including information about IBD, progressive muscle relaxation, thermal biofeedback, and cognitive coping strategies), however, found the therapy helpful in giving them better ability to cope with the disease.

IBD patients with high anxiety scores participated in an 8 session group training program dealing with somatic and psychosocial factors of IBD and stress management ${ }^{76}$. The patients were satisfied with the training, but 6 months after the training, none of the psychological instruments indicated a significant change.

\section{Results of psychotherapy studies}

The results of the psychotherapy studies can be summarized as follows: only one study showed an (indirect) influence of psychotherapy on the somatic course of the illness as fewer rehospitalizations and operations ${ }^{52}$. Most other studies failed to show such an influence. The results of the largest psychotherapy study were not statistically significant ${ }^{53}$. Another studies illustrated the impact of a stress management program on disease related symptoms such as fatigue, diarrhea, constipation, and abdominal pain $^{67,72}$. Some studies showed that psychotherapy influences psychological factors such as depression, anxiety, coping, and stress index ${ }^{52,72,73}$, but this could not be repeated in others ${ }^{53,74-76}$. Patients often believed they had profited from the intervention ${ }^{53,67,72,74-76}$. The studies used very different psychotherapeutic methods (individual and group therapy, psychodynamic methods, behavioral therapy, relaxation therapy, and stress management training), with more frequent use of stress management training. Given the dearth of studies, it is not possible to decide whether one therapy is superior to another. Psychodynamic therapies and behavior therapy appear to have had similar results.

Conclusion based on review of psychotherapy studies in $\mathrm{IBD}^{50}$ :

- Psychotherapy does not affect the course of disease itself but influences the outlook of the patients and how they deal with their illness. Psychotherapy appears to have a positive impact on the patients' depression and anxiety and helps them cope with their illness. Somatic effects were found only seldom and inconsistently. In most of the studies, patients considered psychotherapeutic intervention as helpful in coping with the illness.

- Psychotherapy seems to be ineffective in patients already in the subclinical range before the intervention, when no further improvement is possible.

- The demand for psychotherapy varies significantly. A questionnaire distinguish the demand for certain types of psychological care for IBD patients (intensive/professional psychotherapy, disease-oriented counseling, and integrated psychosomatic care with focus on the interaction of bio-psycho-social state of the patient) ( ref. $\left.^{77}\right)$.

- There is no proof that one therapy is superior to another. So far, there has not been a systematic comparison between the various therapies.

- Patients with Crohn's disease or ulcerative colitis might respond differently to psychotherapy. Overall, Crohn's disease patients have more psychological complaints ${ }^{42}$ which indicates a different starting position or a mentally and physically more challenging illness. Future studies should take this into consideration.

Overall, the existing results give no general indication that patients with IBD should undergo psychotherapeutic treatment. There appear to be "risk patients" in whom psychosocial components have a bigger influence on the course of disease than in other patients. These would probably benefit from psychotherapeutic treatment. The risk factors are: obvious psychopathology, especially depressive symptoms, (chronic) mental stress, interaction of stress and symptoms, dysfunctional coping techniques. A gastroenterologist considering psychotherapy or psychologist consultation for a IBD patient should ask following questions: 
1. Is the patient under a lot of stress that could possibly trigger relapses?

2. How is the patient coping with the disease?

3. Does he or she express signs of depression?

4. Does the patient have a social support system?

Then the physician can decide, together with the patient and possibly a psychotherapist, about the most appropriate type of intervention. These recommendations are in concordance with the European evidence based guideline on the management of Crohn's disease, which indicates that psychotherapy is useful in IBD patients with psychological disorder, such as depression, anxiety, a reduced quality of life with psychological distress, a maladaptive coping with the illness ${ }^{78}$. Currently, it is not known how or why CBT works, when it works, or how to optimize it so that it renders more robust effect sizes; since $23-30 \%$ patients do not respond adequately to $\mathrm{CBT}^{55,79}$. CBT needs to be extended beyond the small number of academic facilities providing behavioral treatments into routine practice settings where the overwhelming majority of patients with IBS can be found. In short, developing more simplified, powerful, accessible, and cost-effective self management therapies depends on specifying theoretical change mechanisms and testing whether they are responsible for therapeutic improvements ${ }^{80}$. Therapies such as CBT derive their therapeutic value by reducing comorbid psychological distress characteristic of more severe IBS patients ${ }^{63}$. Psychological treatments help patients manage the psychological distress which worsens bowel symptoms and quality of life ${ }^{81}$. This view casts heightened psychological distress as a driving influence of symptom exacerbations and its reduction should be the primary goal of psychological therapies. In other words, CBT presumably improves GI symptoms by reducing comorbid psychological distress.

\section{BARRIERS TO THE TREATMENT AND POSSIBLE EFFECTS OF INTERNET USAGE}

A main barrier to CBT treatment is the acceptability of the treatment by "nonpsychiatric" population. Patients are likely to see a doctor's recommendation of CBT as a belief that symptoms are not real, but are instead imaginary ${ }^{82}$. Patients with "psychosomatic illnesses" often reject any implication that psychological processes affect their condition ${ }^{83}$. Considering the current stigma of mental illness in our society today, this rejection is understandable.

Web-based treatment may play an important role in reducing this gap between demand and supply. In recent years, Web-based approaches have been increasingly used and Internet-delivered treatments showed to be an effective and inexpensive alternative to traditional treatments. Web-based programs cover therapeutic approaches such as behavioral activation, cognitive restructuring, mindfulness/acceptance exercises, and social skills training. Interventions can be delivered programmatically and reli- ably, greatly extending the numbers and types of people who can be reached with services.

\section{CONCLUSION}

This model of irritable bowel syndrome requires both factors to be involved, the biological (prior infection, analgesic consumption, and possible genetic predisposition) and psychosocial (prior or recent severe stress, anxiety, depression, and somatization), which represent the archetypal "psychosomatic" paradigm. Although the full range of factors has yet to be worked out it is unlikely that a wholly biological model will supersede this psychosomatic paradigm.

Although the IBD has predominant physical factors, psychological factors are recognized too, (anxiety and depression after the diagnosis). As research methods develop in the 21 st century, the interaction between psychological and biological variables will become clearer and could lead to treatment methods adjustment, being more holistic.

\section{REFERENCES}

1. Drossman DA, Li Z, Leserman J, Keefe FJ, Hu YJ, Toomey TC. Effects of coping on health outcome among female patients with gastrointestinal disorders. Psychosom Med 2000; 62:309-317.

2. Drossman DA, Creed FH, Olden KW, Svedlund J, Toner BB, Whitehead WE. Psychosocial aspects of the functional gastrointestinal disorders. Gut 1999; 45:II25-II30.

3. Levenstein S. Embracing complexity: what determines quality of life in inflammatory bowel disease? Eur J Gastroenterol Hepatol 2004; 16:1253-1255.

4. Drossman DA. Presidential address: gastrointestinal illness and biopsychosocial model. Psychosom Med 1998; 60:258-267.

5. Walker EA, Gelfand AN, Gelfand MD, Katon WJ. Psychiatric diagnoses, sexual and physical victimization, and disability in patients with irritable bowel syndrome or inflammatory bowel disease. Psychol Med 1995; 25:1259-1267.

6. Drossman DA, Creed FH, Olden KW, Svedlund J, Toner BB, Whitehead WE. Psychosocial aspects of the functional gastrointestinal disorders. Gut 1999; 45:II25-II30.

7. Crohn BB, Ginzburg L, Oppenheimer GD. Regional ileitis. JAMA 1932; 99:1323-1329.

8. Alexander F. Psychosomatic Medicine. New York: Norton; 1950.

9. Mawdsley JE, Rampton DS. Psychological stress and IBD: New insights into pathogenic and therapeutic implications. Gut 2005; 54:1481-91.

10. Pace F, Molteni P, Bollani S, et al. Inflammatory bowel disease versus irritable bowel syndrome: A hospital-based, case-control study of disease impact on quality of life. Scand J Gastroenterol 2003; 38:1031-8.

11. Rao SS, Hatfield RA, Suls JM, Chamberlain MJ. Psychological and physical stress induce differential effects on human colonic motility. Am J Gastroenterol 1998; 93:985-90.

12. Maunder R. Mediators of stress effects in inflammatory bowel disease: not the usual suspects. J Psychosom Res 2000; 48:569-577.

13. Levenstein S, Prantera C, Varvo V, et al. Stress and exacerbation in ulcerative colitis: a prospective study of patients enrolled in remission. Am J Gastroenterol 2000; 95:1213-1220.

14. Jones MP, Wessinger S, Crowell MD. Coping strategies and interpersonal supports in patients with irritable bowel syndrome and inflammatory bowel disease. Clin Gastroenterol Hepatol 2006; 4:474-481. 
15. Graff LA, Walker JR, Lix L, et al. The relationship of inflammatory bowel disease type and activity to psychological functioning and quality of life. Clin Gastroenterol Hepatol 2006; 4:1491-1501.

16. Casellas F, Lopez-Vivancos J, Badia X, Vilaseca J, Malagelada JR. Impact of surgery for Crohn's disease on health-related quality of life. Am J Gastroenterol 2000; 95:177-82.

17. Tang LYL, Nabalamba A, Graff LA, Bernstein CN: A comparison of self-perceived health status in inflammatory bowel disease and irritable bowel syndrome patients from a Canadian national population survey. Can J Gastroenterol 2008; 22:475-483.

18. Sperber AD, Carmel S, Atzmon Y, et al. The Functional Bowel Disorder Severity Index (FBDSI) in a study of patients with the irritable bowel syndrome and fibromyalgia. Am J Gastroenterol 2000; 95:995-998.

19. Whitehead WE, Palsson O, Jones KR. Systematic review of the comorbidity of irritable bowel syndrome with other disorders: what are the causes and implications? Gastroenterology 2002; 122:1140-1156.

20. Creed F. The relationship between psychosocial parameters and outcome in irritable bowel syndrome. Am J Med 1999; 107:74S-80S.

21. Guthrie E, Jackson J, Shaffer J, et al. Psychological disorder and severity of inflammatory bowel disease predict health-related quality of life in ulcerative colitis and Crohn's disease. Am J Gastroenterol 2002; 97:1994-1999.

22. Bernklev T, Jahnsen J, Aadland E, et al, and the IBSEN Study Group. Health-related quality of life in patients with inflammatory bowel disease five years after the initial diagnosis. Scand J Gastroenterol 2004; 39:365-373.

23. Drossman DA, Corazziari E, Talley NJ, Thompson WG, Whitehead WE. Rome II. The Functional Gastrointestinal Disorders Diagnosis, Pathophysiology and Treatment: A Multinational Consensus. 2nd ed. McLean, Va: Degnon Associates; 2000:1-764

24. Creed FH, Ratcliffe J, Fernandes L, et al. Depressive, panic and neurasthenic disorders predict poor outcome in severe irritable bowel syndrome unless suitably treated. Br J Psychiatry 2005; 186:507-515.

25. Halder SL, Locke GR III, Talley NJ, Fett SL, Zinsmeister AR, Melton LJ III. Impact of functional gastrointestinal disorders on health-related quality of life: a population-based case-control study Aliment Pharmacol Ther 2004; 19:233-242.

26. Quartero AO, Post MW, Numans ME, de Melker RA, de Wit NJ. What makes the dyspeptic patient feel ill? A cross sectional survey of functional health status, Helicobacter pylori infection, and psychological distress in dyspeptic patients in general practice. Gut 1999; 45:15-19.

27. Badia X, Mearin F, Balboa A, et al. Burden of illness in irritable bowel syndrome comparing Rome I and Rome II criteria. Pharmacoeconomics 2002; 20:749-758.

28. Drossman DA, Li Z, Leserman J, Toomey TC, Hu Y. Health status by gastrointestinal diagnosis and abuse history. Gastroenterology 1996; 110:999-1007.

29. Talley NJ, Fett SL, Zinsmeister AR. Self-reported abuse and gastrointestinal disease in outpatients: association with irritable boweltype symptoms. Am J Gastroenterol 1995; 90:366-371.

30. Johnson CF. Child sexual abuse. Lancet 2004; 364:462-470.

31. Laws A. Sexual abuse history and women's medical problems. J Gen Intern Med 1993; 8:441-443.

32. Dimenas E, Glise H, Hallerback B, Hernqvist H, Svedlund J, Wiklund I. Well-being and gastrointestinal symptoms among patients referred to endoscopy owing to suspected duodenal ulcer. Scand J Gastroenterol 1995; 30:1046-1052.

33. Biggs AM, Aziz Q, Tomenson B, Creed F. Do childhood adversity and recent social stress predict health care use in patients presenting with upper abdominal or chest pain? Psychosom Med 2003; 65:1020-1028

34. Heaton KW. What makes people with abdominal pain consult their doctor. In: Creed FH, Mayou R, Hopkins A, eds. Medica Symptoms Not Explained by Organic Disease. London: Royal Colleges of Physicians and Psychiatrists; 1992:1-8.
35. Guthrie EA, Creed FH, Whorwell PJ, Tomenson B. Outpatients with irritable bowel syndrome: a comparison of first time and chronic attenders. Gut 1992; 33:361-363.

36. Lydiard RB, Greenwald S, Weissman MM, Johnson J, Drossman DA, Ballenger JC. Panic disorder and gastrointestinal symptoms: findings from the NIMH Epidemiologic Catchment Area project. Am J Psychiatry 1994; 151:64-70.

37. Creed F, Morgan R, Fiddler M, Marshall S, Guthrie E, House A. Depression and anxiety impair health-related quality of life and are associated with increased costs in general medical inpatients. Psychosomatics 2002; 43:302-309.

38. Acosta-Ramirez D, Pagan-Ocasio V, Torres EA, Rodriguez M, Caro O. Profile of the inflammatory bowel disease patient with depressive disorders. Puerto Rico Health Sci J 2001; 20:215-220.

39. Craig TKJ. Abdominal pain. In: Brown GW, Harris TO, eds. Life Events and Illness. New York, NY: Guilford; 1989:233-259.

40. Porcelli P, Leoci C, Guerra V. A prospective study of the relationship between disease activity and psychologic distress in patients with inflammatory bowel disease. Scand J Gastroenterol 1996; 31:792-796.

41. Mittermaier CC, Dejaco C, Waldhoer T, et al. Impact of depressive mood on relapse in patients with inflammatory bowel disease: a prospective 18-month follow-up study. Psychosom Med 2004; 66:79-84.

42. Simren M, Axelsson J, Gillberg R, et al. Quality of life in inflammatory bowel disease in remission: the impact of IBS-like symptoms and associated psychological factors. Am J Gastroenterol 2002; 97:389-396.

43. Walker EA, Katon WJ. Researching the health effects of victimization: the next generation. Psychosom Med 1996; 58:16-17.

44. North CS, Alpers DH, Helzer JE, Spitznagel EL, Clouse RE. Do life events or depression exacerbate inflammatory bowel disease? Ann Intern Med 1991; 114:381-386.

45. Kurina LM, Goldacre MJ, Yeates D, Gill LE. Depression and anxiety in people with inflammatory bowel disease. J Epidemiol Community Health 2001; 55:716-720.

46. Boye B, Jahnsen J, Mokleby K, Leganger S, Jantschek G, Jantschek I, Kunzendorf S, Benninghoven D, Wilhelmsen I, Sharpe M, Blomhoff S, Malt UF, Lundin KE. The INSPIRE study: are different personality traits related to disease-specific quality of life (IBS - Q) in distressed patients with ulcerative colitis and Crohn's disease? Inflamm Bowel Dis 2008; 14(5):680-6.

47. Gerbert B. Psychological aspects of Crohn's disease. J Behav Med 1980; 3:41-58.

48. Raja SN, Williams S, McGee R. Multidimensional health locus of control beliefs and psychological health for a sample of mothers. Soc Sci Med 1994; 39:213-220.

49. Ondersma SJ, Lumley MA, Corlis ME, et al. Adolescents with inflammatory bowel disease: the roles of negative affectivity and hostility in subjective versus objective health. J Pediatr Psychol 1997; 22:723-738

50. Von Wietersheim JV, Kessler H: Psychotherapy with Chronic Inflammatory Bowel Disease Patients: A Review. Inflamm Bowel Dis 2006; 12:1175-1184.

51. O'Connor JF, Daniels G, Flood C, et al. An evaluation of the effectiveness of psychotherapy in the treatment of ulcerative colitis. Ann Int Med 1964; 60:587-602.

52. Künsebeck HW, Lempa W, Freyberger H. Kurz - und Langzeiteffekte ergänzender Psychotherapie bei Morbus Crohn. In: Lamprecht F, ed. Spezialisierung und Integration in Psychosomatik und Psychotherapie. Berlin: Springer; 1987:253-262.

53. Jantschek G, Zeitz M, Pritsch M, et al. Effect of psychotherapy on the course of Crohn's disease. Results of the German prospective multicenter psychotherapy treatment study on Crohn's disease. Scand J Gastroenterol 1998; 33:1289-1296.

54. Maunder RG, Esplen MJ. Supportive-expressive group psychotherapy for persons with inflammatory bowel disease. Can J Psychiatry.2001; 46:622-626.

55. Drossman DA, Toner BB, Whitehead WE, Diamant NE, Dalton CB, Duncan S, Emmott S, Proffitt V, Akman D, Frusciante K, Le T, Meyer K, Bradshaw B, Mikula K, Morris CB, Blackman CJ, Hu 
Y, Jia H, Li JZ, Koch GG, Bangdiwala SI. Cognitive-behavioral therapy versus education and desipramine versus placebo for moderate to severe functional bowel disorders. Gastroenterology 2003; 125:19-31. [PubMed: 12851867]

56. Boyce P, Talley N, Balaam B, et al. A randomized controlled trial of cognitive behavior therapy, relaxation training and routine clinical care for the irritable bowel syndrome. Am J Gastroenterol 2003; 98(10):2209-2218.

57. Levy RL, Olden KW, Naliboff BD, Bradley LA, Francisconi C, Drossman DA, Creed F. Psychosocial aspects of the functional gastrointestinal disorders. Gastroenterology 2006; 130:1447-58. [PubMed:16678558]

58. Department of Health. Treatment Choice in Psychological Therapies and Counseling: Evidence Based Clinical Guidelines. UK Department of Health; 2001.

59. Lackner JM, Jaccard J, Krasner SS, Katz LA, Gudleski GD, Blanchard EB. How does cognitive behavior therapy for irritable bowel syndrome work? A mediational analysis of a randomized clinical trial. Gastroenterology 2007; 133:433-44. [PubMed 17681164]

60. Lackner JM, Jaccard J, Krasner SS, Katz LA, Gudleski GD, and Holroyd K: Self administered cognitive behavior therapy for moderate to severe IBS: Clinical efficacy, tolerability, feasibility. Clin Gastroenterol Hepatol. 2008 August; 6(8): 899-906. doi:10.1016/j. cgh.2008.03.004.

61. Whitehead W, Palsson O. Is rectal pain sensitivity a biological marker for irritable bowel syndrome: psychological influences on pain perception. Gastroenterology 1998; 115:1263-1271.

62. Gibbs-Gallagher N, Palsson OS, Levy RL, et al. Selective recall of gastrointestinal-sensation words: evidence for a cognitive behavioral contribution to irritable bowel syndrome. Am J Gastroenterol 2001; 96(4):1133-1138.

63. Boyce P, Gilchrist J, Talley N. et al. Cognitive-behaviour therapy as a treatment for irritable bowel syndrome: a pilot study. Aust $\mathrm{N}$ Z J Psychiatry 2000; 34:300-309.

64. Greene B, Blanchard EB. Cognitive therapy for irritable bowel syndrome. J Consult Clin Psychol 1994; 62(3):576-582.

65. Vollmer A, Blanchard EB. Controlled comparison of individual versus group cognitive therapy for irritable bowel syndrome. Behav Ther 1998; 29(1):19-33

66. Payne A, Blanchard EB. A controlled comparison of cognitive therapy and self-help support groups in the treatment of irritable bowel syndrome. J Consult Clin Psychol 1995; 63(5):779-786.

67. Garcia-Vega E, Fernandez-Rodriguez C. A stress management programme for Crohn's disease. Behav Res Ther 2004; 42:367-383.

68. Shepanski MA, Hurd LB, Culton K, et al. Health-related quality of life improves in children and adolescents with inflammatory bowel disease after attending a camp sponsored by the Crohn's and Colitis Foundation of America. Inflamm Bowel Dis 2005 11:164-170.
69. Kennedy AP, Nelsen E, Reeves D, et al, and the North-West Regional Gastrointestinal Research Group. A randomized controlled trial to assess the effectiveness and cost of a patient orienteated self management approach to chronic inflammatory bowel disease. Gut 2004; 53:1639-1645.

70. Elsenbruch S, Langhorst J, Popkirowa K, et al. Effects of mindbody therapy on quality of life and neuroendocrine and cellular immune functions in patients with ulcerative colitis. Psychother Psychosom 2005; 74:277-287.

71. Van Dulmen A, Fennis J, Bleijenberg G. Cognitive-behavioral group therapy for irritable bowel syndrome: effects and longterm followup. Psychosom Med 1996; 58(5):508-514.

72. Milne B, Joachim G, Niedhardt J. A stress management program for inflammatory bowel disease patients. J Adv Nurs 1986; 11:561567.

73. Mussell M, Bocker U, Nagel N. Reducing psychological distress in patients with inflammatory bowel disease by cognitive-behavioural treatment: exploratory study of effectiveness. Scand J Gastroenterol 2003; 38:755-762.

74. Waters BM, Jensen L, Fedorak RN. Effects of formal education for patients with inflammatory bowel disease: a randomized controlled trial. Can J Gastroenterol 2005; 19:235-244.

75. Schwarz SP, Blanchard EB. Evaluation of a psychological treatment for inflammatory bowel disease. Behav Res Ther 1991; 29:167-177.

76. Larsson KM, Sundberg Hjelm M, Karlbom U, et al. A group-based patient education programme for high-anxiety patients with Crohn disease or ulcerative colitis. Scand J Gastroenterol 2003; 38:763769.

77. Miehsler W, Weichselberger M, Offerlbauer E, et al. Assessing the demand for psychological care in chronic diseases: development and validation of a questionnaire based on the example of inflammatory bowel disease. Inflamm Bowel Dis 2004; 10:637-645.

78. Caprilli R, Gassuli MA, Escher JC, et al. European evidence based consensus on the diagnosis and management of Crohn's disease: special situations. Gut 2006; 55:36-58.

79. Blanchard, EB. Irritable bowel syndrome: Psychosocial assessment and treatment. APA; 2001.

80. Kazdin AE. Progression of Therapy Research and Clinical Application of Treatment Require Better Understanding of the Change Process. Clin Psychol 2001; 8:143-151.

81. Drossman, DA. Chang, L. Psychosocial factors in the care of patients with GI disorders. In: Yamada, T., editor. Textbook of Gastroenterology. Lippincott-Raven; Philadelphia: 2002. p. 63654.

82. Price JR, Couper J. Cognitive behaviour therapy for adults with chronic fatigue syndrome. Cochrane Review, latest version: August 1998. In: The Cochrane Library. Oxford, England.

83. Surawy C, Hackmann A, Hawton K, et al. Chronic fatigue syndrome: a cognitive approach. Behav Res Ther 1995; 33(5):535544. 